Tropical Journal of Pharmaceutical Research December 2015; 14 (12): 2187-2192

ISSN: $1596-5996$ (print); 1596-9827 (electronic)

(C) Pharmacotherapy Group, Faculty of Pharmacy, University of Benin, Benin City, 300001 Nigeria.

All rights reserved.

Available online at http://www.tjpr.org

Original Research Article

http://dx.doi.org/10.4314/tjpr.v14i12.5

\title{
Chloroquinone Inhibits Cell Proliferation and Induces Apoptosis in Nasopharyngeal Carcinoma Cell Lines
}

\author{
Xin-Qing Yang, Hao Zheng, Qing Ye, Rui-Yu Li and Yong Chen \\ Department of Otolaryngology Head and Neck Surgery, Fujian Provincial Clinical College, Fujian Medical University, China
}

*For correspondence: Email: poiasdmnbzxc@hotmail.com; Tel/Fax: 0086-591-87557768

Received: 21 June 2015

Revised accepted: 26 October 2015

\begin{abstract}
Purpose: To demonstrate the role of chloroquinone (CQ) in inducing apoptosis in HONE-1 and HNE-1, nasopharyngeal carcinoma (NPC) cell lines.

Methods: Water-soluble tetrazolium salt (WST)-1 assay was used for the determination of cell proliferation while an inverted microscope was employed for the analysis of alterations in the morphology of the cells.

Results: CQ treatment led to a significant reduction in the rate of cell proliferation in NPC cells after 48 h. In HONE-1 and HNE-1 cell lines viability was reduced to 89 and $82 \%$, respectively on treatment with $10 \mu M$ concentration of $C Q$ without affecting normal human skin keratinocyte cell line, K38. The expression of Ki67, a marker for proliferation as well as proliferating cell nuclear antigen (PCNA), decreased in the CQ-treated NPC cells. Morphological examination of NPC cells revealed cell apoptosis on treatment with $C Q$ after $48 \mathrm{~h}$. Treatment of NPC cells with $C Q$ induced activation of caspases and DNA was damaged which further confirmed CQ-mediated induction of apoptosis. The level of apoptotic cells in CQ-treated and untreated control HONE-1 cell cultures was 53.67 and $3.78 \%$, respectively $(p<$ 0.05). In addition, $C Q$ treatment decreased reactive oxygen species (ROS) generation in NPC cells.

Conclusion: $C Q$ inhibits cell proliferation of NPC cells by inducing apoptosis via DNA damage, and may be of therapeutic use for the treatment of NPC. However, this requires clinical investigation to ascertain its therapeutic potential.
\end{abstract}

Keywords: Chloroquinone, Caspases, Apoptosis, Nuclear antigen, Nasopharyngeal carcinoma

Tropical Journal of Pharmaceutical Research is indexed by Science Citation Index (SciSearch), Scopus, International Pharmaceutical Abstract, Chemical Abstracts, Embase, Index Copernicus, EBSCO, African Index Medicus, JournalSeek, Journal Citation Reports/Science Edition, Directory of Open Access Journals (DOAJ), African Journal Online, Bioline International, Open-J-Gate and Pharmacy Abstracts

\section{INTRODUCTION}

Nasopharyngeal carcinoma (NPC) develops in the epithelial layer or mucosal coating of the oral cavity, pharynx and larynx. NPC has been reported frequently in people belonging to Southern China and North Africa [1,2]. Use of chemo- and radiotherapy has shown efficient results to restrict the growth of tumors locally in addition to increase in the rate of survival for patients with NPC [3]. However, chemo- and radiotherapy for longer periods is accompanied by spreading of mucositis over larger areas making the consumption of medicines difficult. This necessitates reduction in dosage or even stopping radiotherapy [4]. Clinicians all over the globe have made efforts to develop treatment strategies for nasopharyngeal carcinoma but no satisfactory results have been obtained so far [57]. The present study was aimed to investigate the effect of chloroquinone, a natural isolate on HK1 and C666-1 nasopharyngeal carcinoma cell lines.

Chloroquine (CQ) or $\mathrm{N}^{\prime}$-(7- chloroquinolin-4-yl)$\mathrm{N}, \mathrm{N}$-diethyl-pentane-1,4-diamine, acts as an 
inhibitor of autophagy being administered orally to patients [8]. It is used as an anti-malarial drug and was developed by Bayer Laboratories in the year 1934. Clinically this drug was approved by FDA in 1947 for the treatment of patients with malaria [9]. Some of the uses of $C Q$ and its modified analog, hydrated chloroquinone include as anti-inflammatory candidate for rheumatoid arthritis treatment, lupus erythematosus and amoebic hepatitis. Now-a-days CQ is widely investigated for the inhibition of various types of tumors as well as antagonist against chemokine receptor CXCR4 in pancreatic tumors $[9,10]$.

\section{EXPERIMENTAL}

\section{Chemicals and reagents}

Chloroquinone was purchased from SigmaAldrich (St. Louis, MO, USA). The solvents and reagents were obtained from Sigma-Aldrich (St. Louis, MO, USA).

\section{Cell cultures}

HONE-1 and HNE-1 NPC cell lines were obtained from Shanghai Cell Bank of the Chinese Academy of Sciences (Shanghai, China). The normal human keratinocyte cell line, K38 was purchased from Sigma-Aldrich (St. Louis, MO, USA). The cells were maintained in RPMI-1640 medium (Gibco Life Technologies, Carlsbad, CA, USA) supplemented with $10 \%$ heat inactivated fetal bovine serum (FBS) (FCS; Gibco Life Technologies), $10 \mathrm{U} / \mathrm{mL}$ penicillin (Gibco Life Technologies) and $10 \mu \mathrm{g} / \mathrm{mL}$ streptomycin (Gibco Life Technologies) at $37{ }^{\circ} \mathrm{C}$ in a $5 \% \mathrm{CO}_{2}$ humidified atmosphere.

\section{Cell viability}

The viability of HONE- 1 cells after treatment with $C Q$ was investigated using a water-soluble tetrazolium salt (WST)-1 assay (EZ-CyTox Enhanced Cell Viability Assay kit; DaeiLab Service, Seoul, Korea) according to the manual protocol. For this purpose $2.5 \times 10^{5}$ cells were treated with a range of $\mathrm{CQ}$ concentrations followed by the addition of WST-1 solution. Incubation of the cells for $5 \mathrm{~h}$ was followed by measurement of absorbance at $465 \mathrm{~nm}$ to determine the cell viability using BIO-TELTM (EL800). All the experiments were performed in triplicates.

\section{Quantitative real-time polymerase chain reaction (RT-PCR)}

The cells after reaching subconfluence were treated with $10 \mu \mathrm{M}$ of $\mathrm{CQ}$ or DMSO for $48 \mathrm{~h}$.
TRIzol® reagent (Invitrogen, Carlsbad, CA, USA) was used for the isolation of total-RNA which was then transcribed into cDNA using Advantage cDNA PCR kit® (Invitrogen). TaqMan universal $(50 \mu \mathrm{L})$ PCR master with $\mathrm{ABI}$ prism 7000 Sequence Detection System (Applied Biosystems, Foster City, CA, USA) was used for the quantitative RT-PCR according to the manual protocol.

The primer set and TaqMan probe employed for the experiments were purchased from TaqMan gene expression assay systems. The data were normalized using real time (RT)-PCR glyceraldehyde-3-phosphate dehydrogenase (GAPDH) primers (Applied Biosystems).

\section{Western blotting}

$\mathrm{CQ}$ treated and control cells after $48 \mathrm{~h}$ were washed with PBS and lysed using radio immunoprecipitation assay (RIPA) at $4{ }^{\circ} \mathrm{C}$. The cell lysates were centrifuged at $12000 \mathrm{~g}$ for 15 min to clear the insoluble material. Bradford reagent and BSA standard curve (Pierce, Rockford, IL, USA) was used for the quantification and SDS-PAGE for the resolution of Protein.

The proteins were then transferred to the Immobilon-P Transfer Membranes (Millipore, Bedford, MA, USA) and blocked with $5 \%$ fat. The membrane was incubated overnight with monoclonal mouse anti-glyceraldehyde 3phosphate dehydrogenase (GAPDH), monoclonal mouse anti-proliferating cell nuclear antigen (PCNA) and rabbit anti phospho-histone H2AX (Ser139) (Cell Signaling Technology, Inc., Danvers, MA, USA) antibodies at $4{ }^{\circ} \mathrm{C}$. Amersham ECL Plus western blotting detection reagents (GE Healthcare, USA) was used for the detection of bound secondary antibody. Stripping of the membranes for $45 \mathrm{~min}$ at $37{ }^{\circ} \mathrm{C}$ using stripping buffer (Pierce), reblocking, and probing for either GAPDH or the non-phosphorylated protein was performed as the loading control.

\section{Morphological observation}

Onto 96-well microtiter plates the cells were distributed at a density of $2.5 \times 10^{5}$ cells per well. The cells were then allowed to attain confluence in an incubator under $5 \% \mathrm{CO}_{2}$ atmosphere at 37 ${ }^{\circ} \mathrm{C}$. To each well of the plate $\mathrm{CQ}$ at a concentration of $10 \mu \mathrm{M}$ was added and incubated for 48 h. Leica DM IRB (Leica Microsystems, Wetzlar, Germany) inverted microscope was used for the analysis of alterations in the morphology of the cells.

Trop J Pharm Res, December 2015; 14(12): 2188 


\section{Caspase-3/7 activation assay}

The Apo ONE Homogenous Caspase 3/7 assay kit (Promega, Madison, WI, USA) was used to measure the activation of caspase $3 / 7$ in the HONE-1 cells. The cells were distributed at a density of $2.5 \times 10^{5}$ cells per 96 well plastic plate in DMEM supplemented with $10 \%$ FBS. CQ was added to each well of the plate at a concentration of $10 \mu \mathrm{M}$ along with $10 \%$ FBS for $48 \mathrm{~h}$. Caspase $3 / 7$ reagent was added to each well of the plate followed by agitation of the plates for 45 $\mathrm{min}$ in the dark. The fluorescent plate reader (Wallac Oy, Turku, Finland) was used for the measurement of fluorescence intensity at 365 $\mathrm{nm}$.

\section{Apoptosis assay}

HONE-1 cells at a density of $2.5 \times 10^{5}$ were seeded onto culture plates and allowed to reach confluence. The cells were then treated with 10 $\mu \mathrm{M}$ of $\mathrm{CQ}$ or equal volume of DMSO as the control for $48 \mathrm{~h}$. The cells in all the plates were labelled with FITC-conjugated Annexin V antibody and propidium iodide using Annexin V-FITC apoptosis detection kit I (BD Biosciences, San Jose, USA), according to the manual procedure. Fluorescence-activated cell sorting was used for the detection of positive cells.

\section{Inhibition of reactive oxygen species assay}

For the investigation of the effect of $C Q$ treatment on scavenging reactive oxygen species the procedure developed by Rao was used (18). In this method the scavenging capacity of $\mathrm{CQ}$ was compared with curcumin taken as the standard. The concentration of $C Q$ at which half of the generated reactive oxygen species was scavenged was obtained from the plot of percent inhibition verses CQ concentration used.

\section{Statistical analysis}

The data are expressed as mean \pm SD. For analysis of differences in the data, one-way ANOVA was used. Student's unpaired t-test and SPSS 11.5 statistical software were used for comparison between groups. $P<0.05$ was considered as the statistically significant difference.

\section{RESULTS}

\section{Effect of $C Q$ on cell viability}

Analysis of the effect of $\mathrm{CQ}$ on HONE-1 and HNE-1 NPC cell growth revealed a significant decrease in dose and time-dependent manner (Figure 1). Treatment of HONE-1 and HNE-1 cell lines with $10 \mu \mathrm{M}$ of $\mathrm{CQ}$ led to 89 and $82 \%$, respectively inhibition of cell viability after $48 \mathrm{~h}$. However, exposure of the normal human skin keratinocyte cell line, K38 to $\mathrm{CQ}$ showed no inhibitory effect on cell growth at the same concentration after $48 \mathrm{~h}$.

\section{CQ treatment alters cell morphology}

Effect of $\mathrm{CQ}$ at a concentration of $10 \mu \mathrm{M}$ on the morphology of HONE-1 cells was also examined after $48 \mathrm{~h}$ of treatment. The results showed that $\mathrm{CQ}$ treatment in HONE-1 cells for $48 \mathrm{~h}$ led to a marked decrease in the tendency of adherence and the cells attained rounded shape. The cells in the control culture were found to be flattened as well as adherent after $48 \mathrm{~h}$ (Figure 2). Reduction in the degree of adherence and round cell shape are the markers for cell apoptosis.
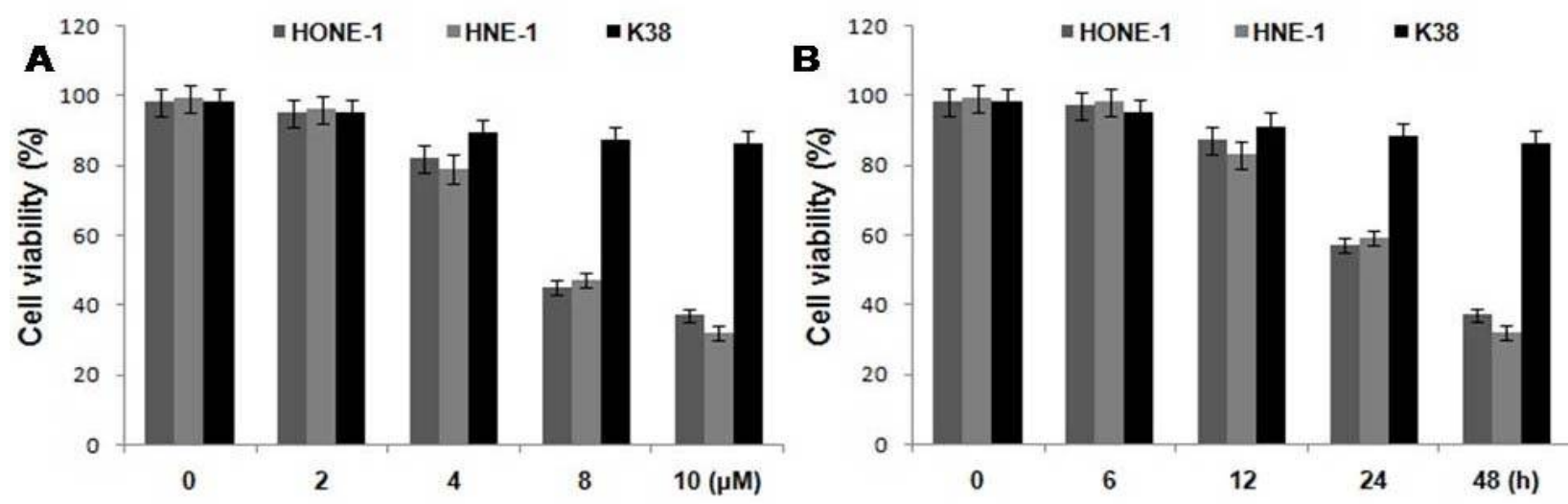

Figure 1: Effect of $\mathrm{CQ}$ on the viability of HONE-1, HNE-1 NPC and K38 cell lines. All the values are expressed as mean \pm standard deviation (SD) 

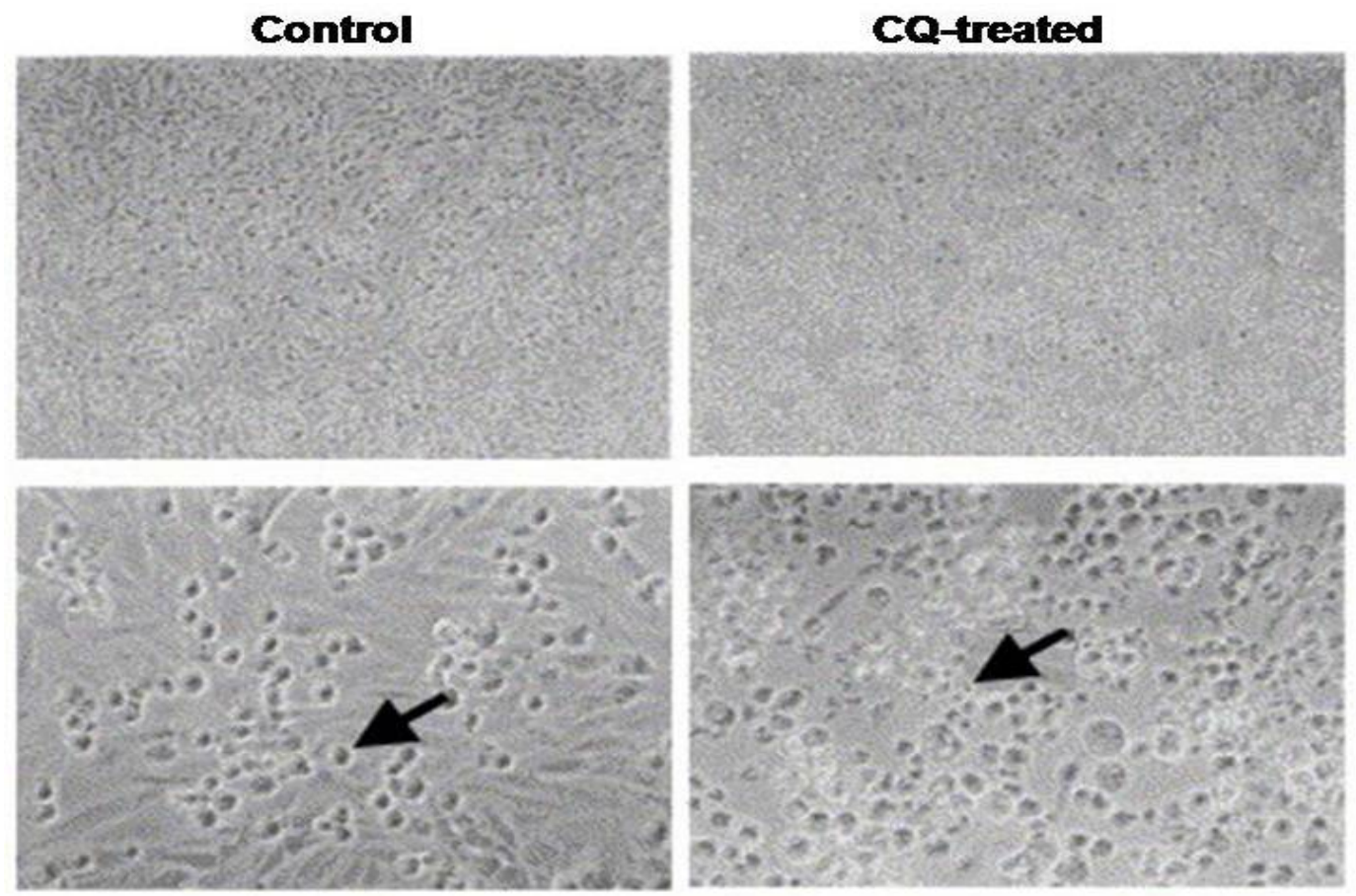

Figure 2: Effect of $\mathrm{CQ}$ on the morphology of HONE-1 nasopharyngeal carcinoma (NPC) cells using inverted microscope after $48 \mathrm{~h}$

\section{Effect of $C Q$ on activation of histone H2AX and caspase-3/7}

Treatment of HONE-1 cells with $\mathrm{CQ}$ for $48 \mathrm{~h}$ led to a significant increase in the activation of histone, H2AX compared to control cells (Figure $3 A)$. Activation of histone protein, H2AX by phosphorylation is a clear indication of damage to cell DNA. In addition, CQ treatment also induced marked increase in the activation of caspase-3/7 in HONE-1 cells (Figure 3B).

\section{Effect of $C Q$ on cell apoptosis}

The results from flow cytometry showed a significant increase in the proportion of apoptotic cells in CQ treated cultures compared to untreated cells. The percentage of apoptotic cells in the $\mathrm{CQ}$ treated and untreated control HONE-1 cells cultures were 53.67 and $3.78 \%$, respectively (Figure 4).
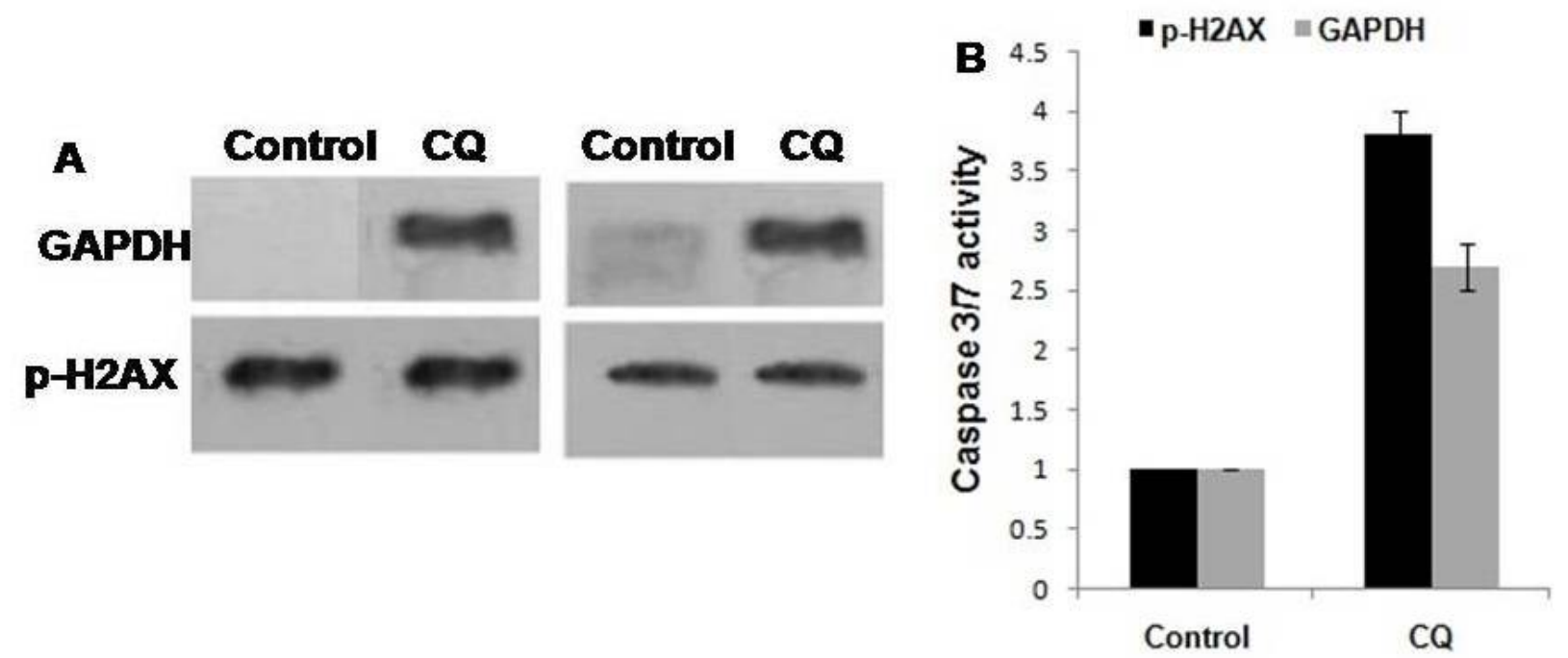

Figure 3: Effect of $C Q$ on the expression of phosphorylated H2AX proteins in NPC cells and activation of caspase- $3 / 7$ in HONE-1 cells 



Figure 4: Flow cytometry analysis of apoptosis in HONE-1 cells using annexin V-fluorescein isothiocyanate (FITC)/propidium iodide (PI) double staining

\section{Effect of $C Q$ on generation of nitric oxide}

$\mathrm{CQ}$ treatment of the cells pretreated with sodium nitroprusside, which acts as the source of nitric oxide, exerted a dose-dependent inhibition on nitric oxide, with generation of nitric oxide in cells treated with $\mathrm{CQ}$ markedly lower than in untreated cells (approx. 0.6 vs $1.0 \mathrm{mg} / \mathrm{mL}$ ).

\section{DISCUSSION}

The results from the present study demonstrated that $\mathrm{CQ}$ treatment inhibits cell proliferation in HONE-1 and HNE-1 NPC cell lines. The inhibition of cell growth was significantly higher in the nasopharyngeal carcinoma cell lines compared to normal human skin keratinocytes. Appearance of the changes in cell morphology like formation of membrane lesions, cell shrinking, breakage of DNA and caspase activation are some of the characteristic features of cell apoptosis [11]. Breakage of cell DNA on treatment with anti-tumor molecules induces phosphorylation of histone protein, H2AX leading to its activation [12,13]. One of the best indicators of damage to cell DNA compared to other methods is the phosphorylation of histone $\operatorname{H} 2 A X[12,14]$. The results from the current study showed that $\mathrm{CQ}$ treatment induced a marked increase in the phosphorylation of H2AX at Ser 139. It has been reported that activation of caspases plays a vital role in the induction of cell apoptosis in various types of tumors [15]. Our results showed that $\mathrm{CQ}$ treatment induced activation of caspases in HONE-1 NPC cells.

It is reported that molecules possessing phenolic scaffolds inhibit generation of reactive oxygen species including NO [16,17]. The reactive oxygen species are involved in inducing damage to cell membranes by peroxidation of membrane lipids [18]. The results from our study showed that $\mathrm{CQ}$ treatment led to scavenging of reactive oxygen species under acellular conditions. Thus $\mathrm{CQ}$ can be a promising agent for prevention of damage caused by the generation of reactive oxygen species in various types of disorders.

\section{CONCLUSION}

CQ treatment in nasopharyngeal carcinoma cell lines inhibits cell proliferation and induces apoptosis. Thus, CQ is a promising agent for the treatment of nasopharyngeal carcinoma.

\section{REFERENCES}

1. Wei WI, Sham JS. Nasopharyngeal carcinoma. Lancet 2005; 365: 2041-2054.

2. Tao $Q$, Chan AT. Nasopharyngeal carcinoma: molecular pathogenesis and therapeutic developments. Expert Rev Mol Med 2007; 9: 1-24.

3. Forastiere $A A$, Trotti $A$. Radiotherapy and concurrent chemotherapy: a strategy that improves locoregional control and survival in oropharyngeal cancer. J Nat Cancer Inst 1999; 91: 2065-2066. 
4. Groome PA, O'Sullivan $B$, Mackillop WJ, Jackson $L D$, Schulze K, Irish JC, et al. Compromised local control due to treatment interruptions and late treatment breaks in early glottis cancer: population-based outcomes study supporting need for intensified treatment schedules. Int J Radiat Oncol Biol Phys 2006; 64: 1002-1012.

5. van Leeuwen IMM, Laín S. Pharmacological manipulation of the cell cycle and metabolism to protect normal tissues against conventional anticancer drugs. Oncotarget 2011; 2: 274-276.

6. Cao $H$, Graves $D$, Anderson $R$. Cinnamon extract regulates glucose transporter and insulin-signaling gene expression in mouse adipocytes. Phytomed 2010; 17: 1027-1032.

7. Bandar E. Pharmaceutical applications and phytochemical profile of Cinnamomum burmannii. Pharmacog Rev 2012; 6: 125-131.

8. Carew JS, Espitia CM, Esquivel JA. J Biol Chem 2011; 286: 6602-6613.

9. Solomon VR, Lee H. Eur J Pharmacol 2009; 625: 220233.

10. Kim J, Yip ML, Shen X. PLoS One 2012; 7: e31004.

11. Unlu M, Ergene E, Unlu G, Zeytinoglu $H$ and Vural $N$ : Composition, antimicrobial activity and in vitro cytotoxicity of essential oil from Cinnamomum zeylanicum Blume (Lauraceae). Food Chem Toxicol 2010; 48: 3274-3280

12. Dickey J, Redon C, Nakamura A, Baird B, Sedelnikova $O$ and Bonner W: H2AX: functional roles and potential applications. Chromosomes 2009; 118: 683-692

13. Kuo $L$ and Yang L: Gamma-H2AX - a novel biomarker for DNA double-strand breaks. In Vivo2008; 22: 305-309

14. Ayoub N, Jeyasekharan A, Bernal J and Venkitaraman A: Paving the way for H2AX phosphorylation: chromatin changes in the DNA damage response. Cell Cycle 2009; 8: 1494-1500.

15. Chung W, Seung H, Jae W. 2-Hydroxycinnamaldehyde inhibits SW620 colon cancer cell growth through AP1 inactivation. J Pharmacol Sci 2007; 104: 19-28.

16. Seung $H$, Sun $Y$, Dong J. Inhibitory effect of 2hydroxycin $n$ namaldehyde on nitric oxide production through inhibition of NFKB activation in RAW 264.7 cells. Biochem Pharmacol 2005; 69: 791-799.

17. Jagetia S, Balgia M, Babu K. Evaluation of nitric oxide scavenging activity of certain herbal formulation in vitro. Phytother Res 2004; 18: 561-565.

18. Korkmaz B, Buharalioglu K, Sahan-Firat S, Cuez T, Demiryurek $T$, Tunctan $B$. Activation of MEK1/ERK1/2/iNOS/sGC/PKG pathway associated with peroxynitrite formation contributes to hypotension and vascular hyporeactivity in endotoxemic rats. Nitric Oxide 2011; 24: 160-172. 